\title{
Factors predicting a poor life prognosis in rheumatoid arthritis: an eight year prospective study
}

\author{
C C ERHARDT, P A MUMFORD, P J W VENABLES, AND R N MAINI
}

From the Department of Immunology of Rheumatic Diseases, Charing Cross Hospital, Fulham Palace Road, London, and the Kennedy Institute of Rheumatology, Bute Gardens, London

SUMmaRY This prospective study evaluates the usefulness of clinical features and measurements of circulating immune complexes and autoantibodies for identification of patients with rheumatoid arthritis with a poor life prognosis. One hundred and seven hospital clinic patients, 64 with extra-articular manifestations, were followed up for a mean period of eight years, during which 50 deaths occurred. Comparison with an age and sex matched control population showed an increased incidence of deaths from myocardial infarction, pneumonia, and complications of rheumatoid arthritis. Patients with cutaneous ulcers, vasculitic rash, neuropathy, and scleritis had a higher mortality than patients whose disease was confined to the joints. Positive serological tests for precipitating antibodies to soluble cellular antigens and cryoglobulinaemia also predicted a poor prognosis. Eleven out of 12 patients $(92 \%)$ with antibodies to soluble cellular antigens died compared with 21 out of 64 patients $(33 \%)$ without antibodies. The presence of cryoglobulinaemia was associated with almost a twofold higher mortality. The laboratory measurements may reflect immunopathogenic mechanisms which lead to the occurrence of extraarticular disease features and reduce life expectancy.

Key words: mortality, vasculitis, antigen-antibody complex, cryoglobulinaemia, autoantibodies.

Several previous studies on the mortality of patients suffering from rheumatoid arthritis have shown that those attending hospitals for treatment of their condition have a modestly reduced life expectancy compared with control populations. ${ }^{1-12}$ Some investigators have shown that mortality is greater among patients with more severe disease as assessed by the number of American Rheumatism Association disease criteria, ${ }^{13}$ functional grading, ${ }^{6}{ }^{14}$ and the presence of serum IgM rheumatoid factor. ${ }^{6}$

Patients with rheumatoid arthritis whose disease is complicated by extra-articular features have a higher mortality than those without these manifestations. ${ }^{15}$ Vascular, granulomatous and visceral lesions in patients with rheumatoid arthritis are associated with the presence of circulating immune complexes, particularly those detected by cryoglobulin formation. ${ }^{16}{ }^{17}$ Patients with extraarticular rheumatoid disease have also been found to have a higher incidence of antinuclear factors

Accepted for publication 25 March 1988.

Correspondence to Dr C C Erhardt, Bromley Hospital, Cromwell Avenue, Bromley, Kent BR2 9AJ. detected by immunofluorescence ${ }^{18}$ and precipitation methods. ${ }^{19}$ In the present study we investigated the possibility that measurements of circulating immune complexes and precipitating antibodies to soluble cellular antigens may assist in the identification of patients with rheumatoid arthritis with a bad prognosis. A cohort of patients with rheumatoid arthritis with well documented clinical and serological features has been followed up for seven to 10 years and the mortality related to their clinical and laboratory variables at the onset of the study.

\section{Patients and methods}

One hundred and eight patients with rheumatoid arthritis, classified as classical or definite according to American Rheumatism Association criteria, ${ }^{20}$ were identified in the period June 1976 to April 1979. Entry to the study was selective for patients with extra-articular disease features and patients admitted to hospital. A reference group comprised patients attending the outpatient clinic for rheumatoid arthritis who did not have extra-articular 
disease. Patients were clinically documented on a proforma with special reference to extra-articular disease manifestations.

Follow up information until the end of 1985 was obtained on all but one patient from hospital records, general practitioner records, and coroners' officers. Copies of death certificates were obtained from the National Health Service Central Registry. The direct cause of death and the underlying antecedent cause of death were selected according to rules given in the International Classification of Diseases. $^{21}$

Blood was clotted and serum separated at $37^{\circ} \mathrm{C}$ for measurement of cryoglobulins. ${ }^{17}$ Serum aliquots were rapidly frozen and stored at $-70^{\circ} \mathrm{C}$ for measurement of $\mathrm{C} 1 \mathrm{q}$ binding ${ }^{22}$ and at $-20^{\circ} \mathrm{C}$ for measurement of IgM rheumatoid factor, ${ }^{23}$ antinuclear factor, and precipitating antibodies to rabbit thymus extract ${ }^{19}$ and rheumatoid arthritis nuclear antigen. ${ }^{24}$

Survival of the patients with rheumatoid arthritis was compared with that of a control age adjusted population created from the Office of Population Censuses and Surveys for England and Wales for 1981 , the modal year of study. ${ }^{25}$ The same figures were used to base calculations, using the Poisson distribution, on the probability of observing by chance the numbers of deaths from individual causes in the patients with rheumatoid arthritis. Variables were examined for power to predict mortality using $\chi^{2}$ analysis and the Cox survival model. ${ }^{26}$

\section{Results}

CHARACTERISTICS OF THE SAMPLE OF

PATIENTS WITH RA

The patients were divided into a group of 44 patients (41\%) without extra-articular disease manifestations and a group of 64 patients (59\%) with extra-articular disease (Table 1). The ages of the two groups of patients did not differ significantly. The group of patients with extra-articular disease had a significantly longer disease duration than the group with joint disease alone. The sex ratio of all the patients in the study was $F: M=71: 37$, i.e., 1.9 , but the sex ratio of the group with joint disease only was $F: M=6 \cdot 3$, whereas in the group of patients with extra-articular disease it was $1 \cdot 1$. Of the individual extra-articular manifestations, only pulmonary disease was commoner in men ( $\mathrm{F}: \mathrm{M}=0 \cdot 6)$.

The presence in the serum of raised levels of IgM rheumatoid factor, cryoglobulins, immune complexes detected by $\mathrm{Clq}$ binding, antinuclear factors, and precipitating antibodies to soluble cellular antigens were all commoner in patients with extraarticular disease. The presence of serum cryoglobu-
Table 1 Characteristics of the patients with rheumatoid arthritis

\begin{tabular}{lll}
\hline & $\begin{array}{l}\text { With joint } \\
\text { disease only }\end{array}$ & $\begin{array}{l}\text { With } \\
\text { granulomatous, } \\
\text { vascular, or } \\
\text { visceral } \\
\text { involvement }\end{array}$ \\
& & \\
& & 64 \\
\hline Number of patients & 44 & $57 \cdot 5$ \\
Median age (years) & 61 & \\
Median duration of disease & & 10 \\
$\quad$ (years) & $3 \cdot 5$ & $33: 31$ \\
Female:male & $38: 6$ & 83 \\
IgM rheumatoid factor & & 70 \\
(DAT* >1/16) (\%) & 55 & 79 \\
Cryoglobulinaemia (\%) & 7 & 61 \\
C1q binding raised (\%) & 55 & 29 \\
ANF* present (\%) & 31 & 32 \\
PASCA* present (\%) & 0 & \\
RANA* antibodies (titre & 36 &
\end{tabular}

${ }^{*} \mathrm{DAT}=$ differential agglutination titre; $\mathrm{ANF}=$ antinuclear factor by immunofluorescence, PASCA = precipitating antibodies to soluble cellular antigens; RANA = rheumatoid arthritis nuclear antigen.

lins and precipitating antibodies to soluble cellular antigens showed the strongest correlation with extra-articular manifestations. There was no significant difference in the prevalence of antibodies to rheumatoid arthritis nuclear antigen in the serum of patients with and without extra-articular manifestations.

\section{CLINICAL FEATURES ASSOCIATED WITH} MORT A L IT Y

The mean follow up period for patients in this study was eight years. Over this period 50 patients $(47 \%)$ died. As shown in previous studies ${ }^{13}$ there was a trend towards higher mortality in male patients than in female patients (Table 2). Mortality was significantly related to disease severity as judged by whether patients fulfilled classical or definite American Rheumatism Association criteria for rheumatoid arthritis. Mortality was also related to duration of disease: patients who died had a longer disease duration at entry to the study (median 10 years) then those who are alive (median 5 years) $(p<0.01)$.

The survival of patients with joint disease alone was not significantly different from that of an age matched control population created from Office of Population Censuses and Surveys statistics for England and Wales in 1981. The mortality of both female and male patients with extra-articular disease manifestations was significantly greater when compared with the curves for both the control population and patients with joint disease alone (Fig. 1).

The relation of mortality to individual extraarticular manifestations of disease was also 
Table 2 Rheumatoid arthritis: clinical features associated with mortality

\begin{tabular}{lccc}
\hline & $\begin{array}{l}\text { Number of } \\
\text { patients }\end{array}$ & $\begin{array}{l}\text { Number of } \\
\text { deaths }\end{array}$ & $\begin{array}{c}\text { Percentage } \\
\text { mortality }\end{array}$ \\
\hline All patients & 107 & 50 & 47 \\
Women & 71 & 29 & 41 \\
Men & 36 & 21 & 58 \\
Classical RA & 63 & 35 & 56 \\
Definite RA & 44 & 15 & 34 \\
Joint disease alone & 44 & 11 & 25 \\
Joint disease + rheumatoid nodules & 19 & 7 & 37 \\
Other extra-articular disease* & 44 & 32 & $73<0.001 \dagger$ \\
Nail fold infarcts & 12 & 7 & 58 \\
Cutaneous ulcers & 10 & 9 & 90 \\
Vasculitic rash & 3 & 3 & 100 \\
Necrotising polyarteritis & 2 & 2 & 100 \\
Neuropathy: sensory & 7 & 6 & 86 \\
sclensoritis & 4 & 3 & 75 \\
Pulmonary disease: & 10 & 9 & 90 \\
$\quad$ Interstitial pneumonia & 12 & 8 & 67 \\
$\quad$ Airways disease & 6 & 4 & 100 \\
$\quad$ Nodules & 2 & 2 & \\
\hline
\end{tabular}

*This group comprises the patients with the vascular and visceral manifestations shown below.

$\dagger$ The probability of observing this number of deaths by chance in a sample of patients drawn from a population with joint disease only.
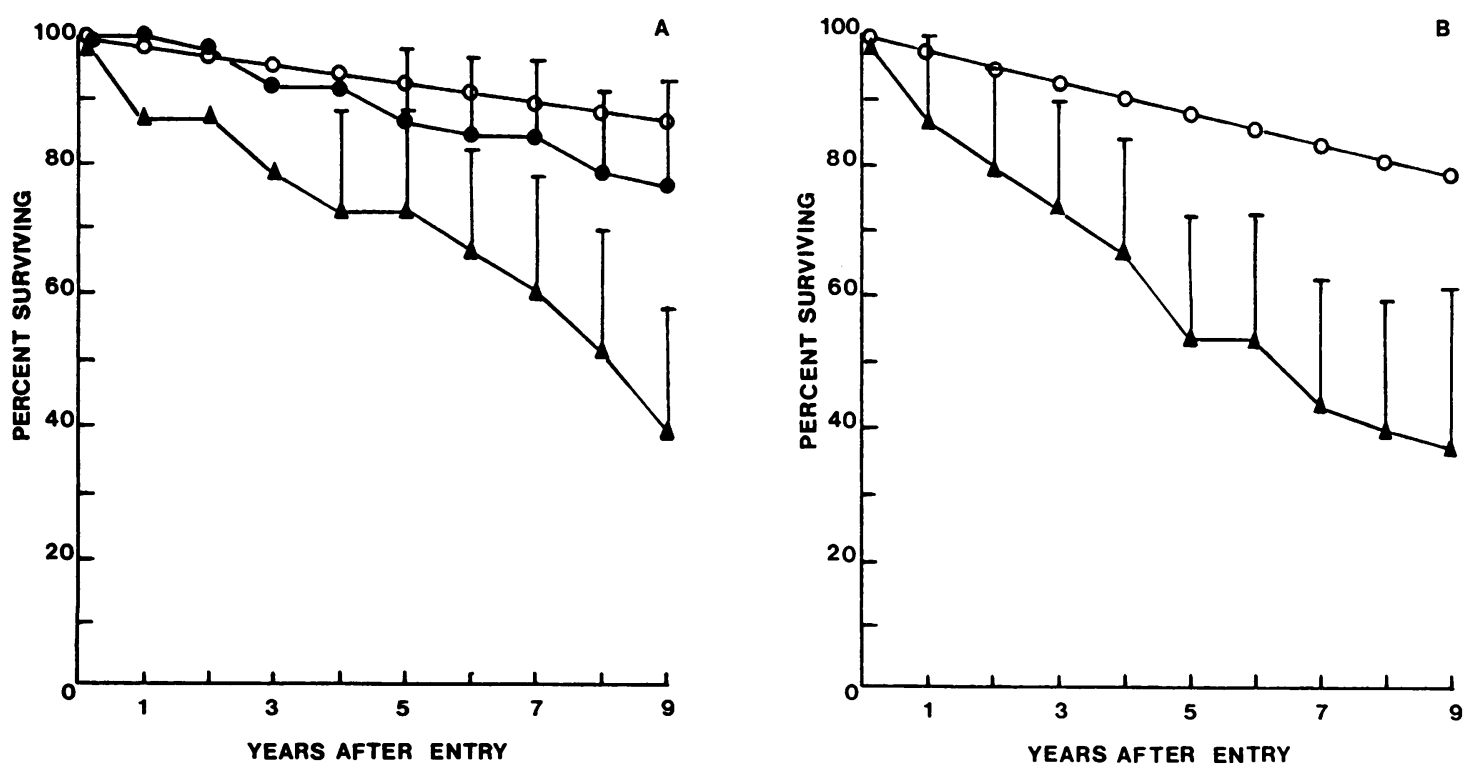

Fig. 1 Survival of hospital clinic patients with rheumatoid arthritis compared with age adjusted population data for England and Wales. $(A)$ Women; $(B)$ men. $\mathrm{O}-\mathrm{O}=$ survival of whole population; $-\mathrm{O}=$ survival of female patients with rheumatoid arthritis and joint disease only $(n=38) ; \boldsymbol{\Delta}-\boldsymbol{\Delta}=$ survival of patients with rheumatoid arthritis and extra-articular disease (33 women, 30 men). Bars represent $95 \%$ confidence intervals. The curve for male patients with joint disease alone is not drawn because of the small number $(n=6)$. 


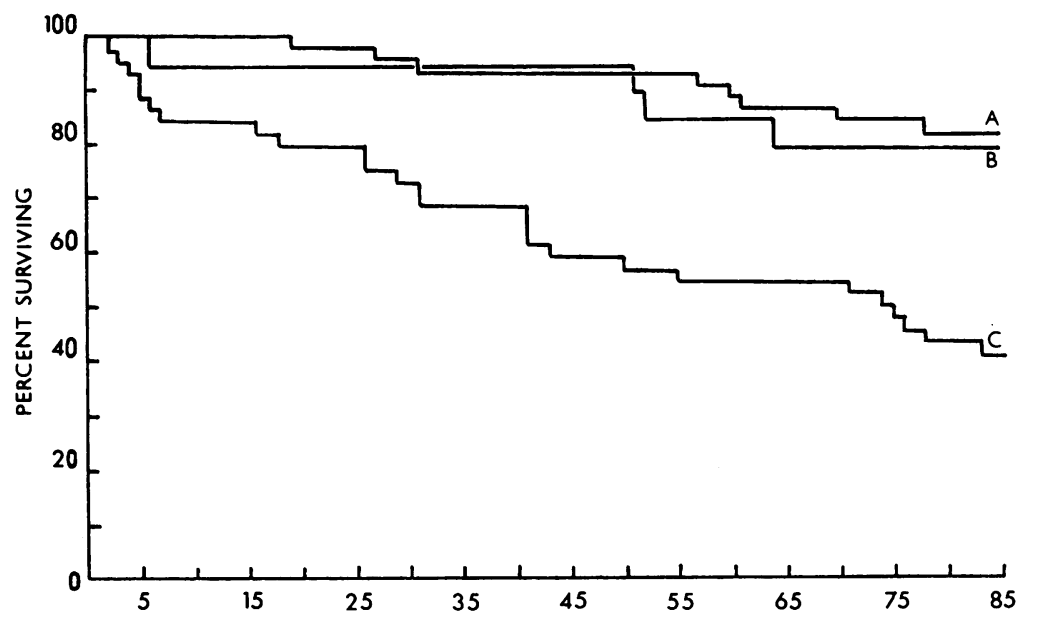

Fig. 2 Survival curves of patients with rheumatoid arthritis. $A=$ survival of patients with joint disease only $(n=43) ; B=$ survival of patients with subcutaneous rheumatoid nodules as the sole extra-articular manifestation ( $n=19) ; C=$ survival of patients with vascular and visceral extraarticular manifestations $(n=45)$.

INTERVAL BETWEEN ENTRY TO STUDY AND DEATH (MONTHS)

examined. The survival curve for patients with subcutaneous rheumatoid nodules as the sole extraarticular feature was not significantly different from that of patients without extra-articular disease (Fig.

Table 3 Rheumatoid arthritis: laboratory variables associated with mortality

\begin{tabular}{|c|c|c|c|}
\hline & $\begin{array}{l}\text { Number of } \\
\text { patients }\end{array}$ & $\begin{array}{l}\text { Number of } \\
\text { deaths }\end{array}$ & $\begin{array}{l}\text { Percentage } \\
\text { mortality }\end{array}$ \\
\hline \multicolumn{4}{|c|}{ IgM rheumatoid factor: } \\
\hline Normal & 31 & 11 & 35 \\
\hline Raised & 76 & 39 & 51 \\
\hline \multicolumn{4}{|c|}{ Cryoglobulin: } \\
\hline Normal & 60 & 21 & 35 \\
\hline Raised & 47 & 29 & $62 \mathrm{p}<0.02 \dagger$ \\
\hline \multicolumn{4}{|c|}{$\mathrm{C} 1 \mathrm{q}$ binding: } \\
\hline Normal & 32 & 10 & 31 \\
\hline Raised & 72 & 37 & 51 \\
\hline \multicolumn{4}{|l|}{ ANF*: $^{*}$} \\
\hline Absent & 46 & 19 & 41 \\
\hline Present & 44 & 24 & 55 \\
\hline \multicolumn{4}{|l|}{ PASCA*: } \\
\hline Absent & 64 & 21 & 33 \\
\hline Present & 12 & 11 & $92 \mathrm{p}<0.001 \dagger$ \\
\hline \multicolumn{4}{|c|}{ RANA $^{*}$ antibodies: } \\
\hline Normal & 55 & 24 & 44 \\
\hline Raised & 28 & 14 & 50 \\
\hline
\end{tabular}

2). The survival of patients with Sjögren's syndrome $\vec{\oplus}$ and Raynaud's phenomenon (considered separately) was also not significantly reduced. Vascular and visceral extra-articular disease features were frequently observed together in a single patient and were grouped together. Patients with these manifestations had a significantly increased mortality than those without extra-articular disease. The reduced survival of these patients appeared early in the study and persisted throughout the follow up period. Mortality appeared excessive in patients considered to have features of an active vasculitic process (cutaneous ulcers, vasculitic rash, neuropathy, and necrotising polyarteritis) and scleritis.

LABORATORY FEATURES ASSOCIATED WITH MOR T A L I T Y

Mortality was significantly increased in patients whose serum contained precipitating antibodies to을. soluble cellular antigens and cryoglobulins (Table N 3 ). There was a trend towards increased mortality in patients whose serum contained IgM rheumatoid 0 factor (differential agglutination titre greater than $N$ 1/16) and immune complexes detected by C1qO binding. Antinuclear factor by immunofluorescenceo and rheumatoid arthritis nuclear antigen antibodies did not predict mortality.

As it was found that mortality was related to several demographic, clinical, and laboratory measurements a multivariate analysis was per- $\stackrel{\mathbb{Q}}{\mathcal{Q}}$ formed to show to what extent these covariates were $\stackrel{\mathbb{Q}}{\Omega}$ independent or interrelated predictors of mortality. The Cox regression model was used, in which the predictive value of the clinical features and laboraz 
tory measurements mentioned in Tables 1 and 2 was assessed by entering or excluding the measurements in a stepwise fashion. The analysis yielded four variables which gave a significant improvement in the model (Table 4). Of the two demographic variables entered (age and sex), only age was significant. The model confirmed the importance of extra-articular disease as a clinical predictor and precipitating antibodies to soluble cellular antigens and cryoglobulinaemia as laboratory predictors of mortality. Disease duration, although related to the presence of extra-articular disease by univariate analysis, was a weaker predictor of death in the model.

\section{CAUSES OF DEATH}

Rheumatoid arthritis was considered the underlying antecedent cause of death in 10 patients. Direct causes of death in this group included pneumonia in five patients, of whom two suffered from preceding interstitial pneumonia and three were bed bound or debilitated. The direct causes of death in three additional female patients were constrictive pericarditis, renal failure due to amyloidosis, and cervical myelopathy. One woman aged 49 died of an arrhythmia following aortic valve replacement for aortic incompetence ascribed to systemic rheumatoid disease. A 49 year old man died of myocardial infarction secondary to coronary arteritis associated with widespread rheumatoid vasculitis.

Patients in this study had an increased relative risk of dying from diseases of the circulatory and respiratory systems (Table 5). Fourteen patients died of myocardial infarction, of whom three men had manifestations of active vasculitis at the time of entry to the study. Rheumatoid arthritis was considered to be the underlying antecedent cause of death in one of these patients (mentioned above).

Table 4 Cox model survival analysis of predictors of mortality

\begin{tabular}{|c|c|c|c|c|c|}
\hline Step & Variable & Units/code, range & $\begin{array}{l}\text { Regression } \\
\text { coefficient }\end{array}$ & $\chi_{\chi^{2}}^{\text {Improvement } \dagger}$ & $\begin{array}{l}\text { Improvement } \\
p \text { value }\end{array}$ \\
\hline 1 & Age & Years, 25-84 & 0.088 & 23 & $<0.001$ \\
\hline 2 & Extra-articular features & Absent/present & $1 \cdot 36$ & 21 & $<0.001$ \\
\hline 3 & PASCA* & Absent/present & 1.41 & 19 & $<0.001$ \\
\hline 4 & Cryoglobulinaemia & $\mathrm{mg} / 1,0-65$ & 0.034 & 8 & 0.004 \\
\hline
\end{tabular}

*PASCA = precipitating antibodies to soluble cellular antigens.

†The values describe the extent to which the entry of each variable in a stepwise manner improves the model. They are derived from the BMDP 2L program. ${ }^{26}$

Table 5 Underlying cause of death of patients with rheumatoid arthritis compared with age adjusted population

\begin{tabular}{|c|c|c|c|c|c|c|}
\hline \multirow{2}{*}{$\begin{array}{l}\text { ICD* } \\
\text { group }\end{array}$} & \multirow[t]{2}{*}{ Cause of death } & \multicolumn{2}{|c|}{ Observed deaths } & \multirow{2}{*}{$\begin{array}{l}\text { Expected } \\
\text { deaths }\end{array}$} & \multirow{2}{*}{$\begin{array}{l}\text { Observed/ } \\
\text { Expected }\end{array}$} & \multirow{2}{*}{$\begin{array}{l}p \\
\text { Valuet }\end{array}$} \\
\hline & & Total & $\begin{array}{l}\text { Sex } \\
\text { distribution }\end{array}$ & & & \\
\hline $\mathbf{I}$ & Infections & 1 & F1 & 0.03 & $33 \cdot 3$ & - \\
\hline \multirow[t]{2}{*}{ II } & Neoplasms & 6 & M1 & $2 \cdot 2$ & 0.5 & - \\
\hline & & & F5 & $2 \cdot 8$ & $1 \cdot 8$ & 0.09 \\
\hline \multirow[t]{4}{*}{ VII } & Circulatory system & 20 & M12 & $4 \cdot 0$ & 3.0 & 0.0006 \\
\hline & & & F8 & $4 \cdot 4$ & $1 \cdot 8$ & 0.04 \\
\hline & Myocardial infarction & 13 & M9 & $1 \cdot 9$ & $4 \cdot 7$ & 0.0001 \\
\hline & & & F4 & $1 \cdot 5$ & $2 \cdot 7$ & 0.05 \\
\hline \multirow[t]{4}{*}{ VIII } & Respiratory system & 9 & M5 & $1 \cdot 0$ & $5 \cdot 0$ & 0.003 \\
\hline & & & F4 & $1 \cdot 2$ & $3 \cdot 3$ & 0.03 \\
\hline & Pneumonia & 6 & M3 & 0.4 & $7 \cdot 5$ & 0.01 \\
\hline & & & F3 & 0.8 & $3 \cdot 8$ & 0.04 \\
\hline IX & Digestive system & 2 & $\mathbf{F} 2$ & 0.3 & $6 \cdot 7$ & 0.03 \\
\hline $\mathbf{X}$ & Genitourinary & 1 & M1 & 0.08 & $12 \cdot 5$ & - \\
\hline \multirow[t]{3}{*}{ XIII } & Musculoskeletal & & & & & \\
\hline & system & 10 & M2 & 0.02 & $100 \cdot 0$ & 0.0002 \\
\hline & & & F8 & 0.07 & $114 \cdot 3$ & $10^{-14}$ \\
\hline XVII & Suicide & 1 & F1 & 0.06 & 16.7 & - \\
\hline
\end{tabular}

${ }^{*} \mathrm{ICD}=$ International Classification of Diseases.

†Probability of observing this number of deaths by chance in an age adjusted sample of people drawn from the normal population. 
Pneumonia was the direct cause of death of six patients with no antecedent cause recorded. Pneumonia was the direct cause of death of seven further patients whose underlying antecedent causes of death were chronic obstructive airways disease (one man), carcinoma of the breast (one), and rheumatoid arthritis (five patients mentioned above).

Two patients succumbed to diseases of the digestive system. One patient suffered bowel perforation (the site of perforation was not mentioned on the death certificate) and the other died from pancreatitis.

\section{Discussion}

The object of this prospective study on the mortality of patients with rheumatoid arthritis was to identify clinical features and laboratory variables associated with an increased risk of mortality. Both the clinical documentation and laboratory investigations were performed at the time of entry to the study. Entry to the study was biased towards patients with extraarticular disease and those requiring hospital admission, which may account for the relatively high mortality of the patients in this study compared with previous series. ${ }^{113}$

The group of patients with extra-articular disease showed several characteristics which have been previously described. These included the more frequent occurrence of extra-articular disease manifestations in male patients ${ }^{15}$ whose serum contained IgM rheumatoid factor, ${ }^{27} 28$ cryoglobulins, ${ }^{16}{ }^{17}$ and antibodies to nuclear antigens detected by immunofluorescence. ${ }^{18}$ Many patients from this study were also included in an HLA study, ${ }^{29}$ which showed an association between a haplotype containing DR4 and a subset of male patients with rheumatoid arthritis and extra-articular disease. It was suggested that the HLA haplotype contributed to disease severity in this group of patients.

This study confirms a higher mortality of patients with classical as opposed to definite rheumatoid arthritis $^{13}$ and of patients with extra-articular disease features. ${ }^{15} \mathrm{We}$ observed an increased mortality in patients whose serum contained cryoglobulins or precipitating antibodies to soluble cellular antigens, which might be expected from the association of these laboratory features with extraarticular disease. Multivariate analysis was performed to assess the extent to which these clinical and laboratory variables predicted mortality independently. As expected for a disease generally associated with only a modest reduction in life expectancy the patients's age at entry to the study was the strongest predictor of mortality. The presence of extra-articular clinical features showed the next strongest association with mortality followed by the two laboratory measurements. The additional predictive value of the laboratory measurements may reflect a distinction between $\frac{\bar{\omega}}{\sigma}$ those patients with continuing systemic disease $\overparen{D}$ activity and those with relatively inactive systemic disease but persisting extra-articular features.

In accordance with previous studies ${ }^{49}$ our patients showed an increased risk of mortality from complications of rheumatoid arthritis, circulatory causes, particularly myocardial infarction, and pneumonia. Our observations showed no clear association between individual extra-articular dis- $\stackrel{\infty}{\infty}$ ease manifestations observed at entry into the study $\vec{i}$ and death from a particular cause (data not shown). 을 It is likely that several factors contribute to the observed mortality from myocardial infarction and pneumonia. Coronary arteritis was present in one patient who died of myocardial infarction, but we do not have adequate information on the coronary arteries of the other 13 patients who died from this $\vec{\varnothing}$ cause. Two patients who died from bacterial bronchopneumonia had a preceding interstitial pneumonia, which was considered an extra-articular manifestation of rheumatoid arthritis. Reduced exercise capacity and smoking might have contributed to the increase of deaths from myocardial infarction and pneumonia. Corticosteroid treatment may be a factor contributing to atheroma formation, ${ }^{30} \mathrm{O}$ although Monson and Hall noted an increased mortality from atherosclerotic heart disease in their patients before corticosteroids became available. ${ }^{4}$ Ten patients died from pneumonia in Charing Cross Hospital or while under the care of the rheumatology clinic. None of these patients was taking immunosuppressive drugs at the time of death, $\delta$ though the immunosuppressive action of corticosteroid treatment might have been a factor in eight $ᄋ$ of these patients thus treated.

When our cohort of patients is taken as a whole those who had been treated with prednisolone, gold, $\sim$ penicillamine, and immunosuppressive agents had a higher mortality. Review of the notes and causes of $\tilde{N}$ death of the 31 patients who died while attending Charing Cross Hospital did not show any iatrogenic o deaths. Although we cannot rule out the possibility that these drugs contributed to the deaths of our $\underset{D}{\overparen{D}}$ patients, our observations suggest that the associa- $\stackrel{\infty}{\rightarrow}$ tion results from selection of more severely affected $\tau$ patients for treatment.

The presence of serum cryoglobulin and precipi- $\stackrel{\mathbb{D}}{\overparen{D}}$ tating antibodies to soluble cellular antigens may $\overrightarrow{\mathbb{D}}$ reflect disturbances of the immune system, which $\frac{}{0}$ have a role in causing the increased mortality seen in patients with rheumatoid arthritis and extra- $\frac{\delta}{0}$ 
articular disease. For example, circulating immune complexes have been implicated in the pathogenesis of coronary occlusive disease in experimental models. ${ }^{31}$ We suggest that a similar pathogenic process may underly the high mortality from myocardial infarction. Similarly, the increased incidence of deaths from pneumonia may reflect reduced capability of local immune mechanisms in the lung to deal with infection. Our study has suggested ways of identifying patients in whom these factors may be important, but further work is required to delineate the pathogenesis and optimal treatment.

We thank Dr K D MacRae, Charing Cross and Westminster Medical School, for advice on statistics, Mrs S Webber Spry for typing the manuscript, and the Arthritis and Rheumatism Council for financial support.

\section{References}

1 Cobb S, Anderson F, Bauer W. Length of life and cause of death in rheumatoid arthritis. $N$ Engl J Med 1953; 249: 553-6.

2 Duthie J J R, Brown P E, Truelove L H, Baragar F D, Lawrie A J. Course and prognosis in rheumatoid arthritis. Ann Rheum Dis 1964; 23: 193-202.

3 Uddin J, Kraus A S, Kelly H G. Survivorship and death in rheumatoid arthritis. Arthritis Rheum 1970; 13: 125-30.

4 Monson R R, Hall A P. Mortality among arthritics. J Chronic Dis 1976; 29: 459-67.

5 Lewis P, Hazleman B L, Hanka R, Roberts S. Cause of death in patients with rheumatoid arthritis with particular reference to azathioprine. Ann Rheum Dis 1980; 39: 457-61.

6 Allebeck P, Ahlbom A, Allander E. Increased mortality among persons with rheumatoid arthritis, but where RA does not appear on death certificate. Scand J Rheumatol 1981; 10: 301-6.

7 Allebeck P. Increased mortality in rheumatoid arthritis. Scand J Rheumatol 1982; 11: 81-6.

8 Vandenbroucke J P, Hazevoet H M, Cats A. Survival and cause of death in rheumatoid arthritis: 25-year prospective follow up. J Rheumatol 1984; 11: 158-61.

9 Prior P, Symmons D P M, Scott D L, Brown R, Hawkins C F. Cause of death in rheumatoid arthritis. Br J Rheumatol 1984; 23: 92-9.

10 Mutru O, Laakso M, Isomaki H, Koota K. Ten year mortality and causes of death in patients with rheumatoid arthritis. $\mathrm{Br}$ Med J 1985; 290: 1797-9.

11 Scott D L, Symmons D P M. The mortality of rheumatoid arthritis. Reports on rheumatic diseases. London: Arthritis and Rheumatism Council, 1986: Jan (series 2).

12 Mitchell D M, Spitz P W, Young D Y, Block D A, McShane D J, Fries J F. Survival, prognosis and cause of death in rheumatoid arthritis. Arthritis Rheum 1986; 29: 706-14.

13 Rasker $\mathrm{J} J$, Cosh $\mathrm{J}$ A. Cause and age at death in a prospective study of 100 patients with rheumatoid arthritis. Ann Rheum Dis 1981; 40: 115-20.

14 Pincus T, Callahan L F, Sale W G, Brooks A L, Payne L E,
Vaughn W K. Severe functional declines, work disability and increased mortality in seventy-five rheumatoid arthritis patients studied over nine years. Arthritis Rheum 1984; 27: 864-72.

15 Gordon D A, Stein J L, Broder I. The extra-articular features of rheumatoid arthritis. Am J Med 1973; 54: 445-52.

16 Weisman $M$, Zvaifler N. Cryoglobulinaemia in rheumatoid arthritis. Significance in serum of patients with rheumatoid vasculitis. J Clin Invest 1975; 56: 725-39.

17 Erhardt C C, Mumford P, Maini R N. The association of cryoglobulinaemia with nodules, vasculitis and fibrosing alveolitis in rheumatoid arthritis and their relationship to serum $\mathrm{Clq}$ binding activity and rheumatoid factor. Clin Exp Immunol 1979; 38: 405-13.

18 Ward D J, Johnson G D, Holborow E J. Antinuclear factor in rheumatoid arthritis: its incidence and clinical significance. Ann Rheum Dis 1964; 23: 306-10.

19 Venables P J W, Erhardt C C, Maini R N. Antibodies to extractable nuclear antigens in rheumatoid arthritis: relationship to vasculitis and circulating immune complexes. Clin Exp Immunol 1980; 39: 146-53.

20 A committee of the American Rheumatism Association. Diagnostic criteria for rheumatoid arthritis. 1958 revision. Ann Rheum Dis 1959; 18: 49-53.

21 World Health Organisation. Manual of the international statistical classification of diseases, injuries and causes of death. Ninth Review Conference 1975: Vol 1.

22 Zubler R H, Nydegger U, Perrin L H, et al. Circulating and intra-articular immune complexes in patients with rheumatoid arthritis. J Clin Invest 1976; 57: 1308-19.

23 Cathcart E S, O'Sullivan J B. Standardisation of the sheep cell agglutination test. The use of pooled reference sera and haemagglutination trays. Arthritis Rheum 1965; 8: 530-7.

24 Venables P J W, Roffe L M, Erhardt C C, Maini R N, Edwards J M B, Porter A D. Titres of antibodies to RANA in rheumatoid arthritis and normal sera. Arthritis Rheum 1981; 24: $1459-64$.

25 Office of Population Censuses and Surveys. Mortality statistics 1981: cause; England and Wales. Series DH2. London: HMSO, 1981: No 8.

26 Hopkins A. Survival analysis with covariates-Cox models. In: Dixon W J, ed. BMDP statistical software. Los Angeles: University of California Press, 1985: 576-94.

27 Tomasi T B, Fudenberg H H, Finby N. Possible relationship of rheumatoid factors and pulmonary disease. Am J Med 1962; 33: 243-8.

28 Mongan E S, Cass R M, Jacox R F, Vaughan J H. A study of the relation of seronegative and seropositive rheumatoid arthritis to each other and to necrotising vasculitis. Am J Med 1969; 47: 23-35.

29 Ollier W, Venables P J W, Mumford P A, et al. HLA antigen associations with extra-articular rheumatoid arthritis. Tissue Antigens 1984; 24: 279-91.

$30 \mathrm{Kalbak} \mathrm{K}$. Incidence of arteriosclerosis in patients with rheumatoid arthritis receiving long-term corticosteroid therapy. Ann Rheum Dis 1972; 31: 196-200.

31 Rich A R, Gregory J E. Experimental anaphylactic lesions of the coronary arteries of the 'sclerotic' type, commonly associated with rheumatic fever and disseminated lupus erythematosus. Bulletin of the Johns Hopkins Hospital 1947; 81: 312-24. 